\title{
mRNA at the Synapse: Analysis of a Synaptosomal Preparation Enriched in Hippocampal Dendritic Spines
}

\author{
Marina E. Chicurel, ${ }^{1}$ David M. Terrian, ${ }^{2}$ and Huntington Potter ${ }^{1}$ \\ 'Department of Neurobiology and Program in Neuroscience, Harvard Medical School, Boston, Massachusetts 02115 and \\ ${ }^{2}$ Department of Anatomy and Cell Biology, East Carolina University School of Medicine, Greenville, North Carolina 27858- \\ 4354
}

Previous studies have demonstrated that the branched spines of the mossy fiber-CA3 hippocampal synapse contain a particularly large number of polyribosomes (Chicurel and Harris, $1989,1992)$. We analyzed a preparation of synaptosomes isolated from this region and have found it to contain a restricted RNA population: certain mRNAs, presumably derived from the dendritic spines and the fine astrocytic processes surrounding the pre- and postsynaptic elements of the synapse, are enriched in the synaptosome preparation as compared to the total hippocampus; other mRNAs are less prevalent or altogether absent. In addition, neural BC1, a small noncoding RNA thought to be involved in pre- or posttranslational regulatory processes in dendrites, is a major RNA component of the dendritic spine. These results support the hypothesis that local translational regulation of gene expression may be important in establishing and modulating synaptic function.

[Key words: mRNA localization, hippocampal mRNA, dendritic spines, synaptosomes, synapse]

The highly polarized character of the neuron and its need to coordinate cellular processes at many different locations far from the cell body pose unique regulatory problems. Not only must the neuron establish and maintain a specific distribution of the many molecules involved in synaptic transmission, but it must also have the capability of modifying their activity and concentration so as to mediate and sustain changes in local synaptic strength. One mechanism that may contribute to both the generation and maintenance of neuronal polarity, and which also provides a potential for synaptic plasticity, is the subcellular compartmentalization of the protein synthetic machinery. That is, the targeting of specific RNAs to discrete neuronal domains may be an efficient way of localizing proteins involved in synaptic transmission by establishing local sites for their synthesis. Furthermore, changes in local protein synthesis resulting from changes in transport, turnover, or translation of specific mRNA species could help mediate synaptic plasticity (for discussion, see Steward et al., 1988; Steward and Banker, 1992).

\footnotetext{
Received Jan. 4, 1993; revised Apr. 2, 1993; accepted Apr. 13, 1993.

We thank Dr. Christopher DeFranco for many helpful comments. We also thank Drs. Larry Benowitz and Kenneth Kosik for critical reading of the manuscript. This work was supported by NIH Grants AG08084 and AG09665 to H.P. and AFOSR-89-0531 to D.M.T. M.E.C. is a Howard Hughes Medical Institute predoctoral fellow.

Correspondence should be addressed to Huntington Potter, Department of Neurobiology, Harvard Medical School, 220 Longwood Avenue, Boston, MA 02115.
}

Copyright (C) 1993 Society for Neuroscience $0270-6474 / 93 / 134054-10 \$ 05.00 / 0$
Garner et al. (1988) were the first to clearly observe differential localization of mRNAs outside the neuron cell body. Their in situ hybridization studies on cortical and hippocampal tissue showed that the mRNA coding for MAP-2, a microtubule-associated protein found predominantly in dendrites, was present in both cell body and dendritic layers of these tissues. The mRNA for tubulin, on the other hand, was restricted to the cell body layers. Subsequent in situ hybridization studies of other mRNAs in the nervous system have extended these initial findings. With the use of cultured cells, Kleiman et al. (1990) and Bruckenstein et al. (1990) were able to establish unequivocally the location of MAP-2 mRNA in dendrites and other mRNAs exclusively in cell bodies. Additional studies have revealed the presence of other mRNAs in dendrites (Tucker et al., 1989; Burgin et al., 1990; Strong et al., 1990), axons (Jirikowski et al., 1990; Mohr ct al., 1991), and glial cell processes (Colman et al., 1982; Trapp et al., 1987; Webster et al., 1987; Sarthy et al., 1989; Gillespie et al., 1990; Gould and Mattingly, 1990; Trimmer et al., 1991).

Although in situ hybridization studies have categorized a handful of mRNAs as located either exclusively in the cell soma or in both the soma and processes, they were not able to address the question of mRNA localization in more specialized subcellular domains. First, probes for relatively abundant RNAs are generally required, as low-level expression is difficult to detect by in situ hybridization. Second, except when coupled to electron microscopy (EM), in situ hybridization does not have the requisite spatial resolution to distinguish small subcellular compartments such as dendritic spines. Thus, the best in situ hybridization studies carried out in sections of nervous tissue have shown that even in highly laminated regions, the spatial resolution needed for unequivocal subcellular localization of mRNAs is not rcadily available (Phillips and Steward, 1990). This problem has been partially circumvented by the use of cultured cells (Bruckenstein et al., 1990; Kleiman et al., 1990). However, synapse-associated mRNAs still cannot be distinguished and there is some concern that cultured cells may not accurately reflect their in vivo counterparts. Also, the potential for studying the effect of in vivo manipulation on RNA localization and function is lost.

In order to explore the question of protein synthesis at the synapse, we have developed an experimental system that permits the direct study of synaptic RNA. Specifically, we have been able to isolate a class of hippocampal synaptosomes that have proved particularly well suited for purification and analysis of synaptic RNA. These synaptosomes are derived from the mossy fiber (MF) boutons of the dentate granule cells, which can be isolated in association with the $\mathrm{CA} 3$ dendritic spines and 
the fine astrocytic processes present at the synapse. In contrast to most synapses in which ribosomes are found predominantly at the bases of the dendritic spines (Steward and Levy, 1982), these CA3 branched spines contain particularly large numbers of ribosomes within their cytoplasm (Chicurel and Harris, 1989, 1992), and thus constitute a potentially rich source of postsynaptic RNA. A specially designed isolation procedure yields synaptosomes that include the complete collection of subcellular entities composing the MF-CA3 synapse (Terrian et al., 1988). Because the large CA3 branched spines are embedded within the MF presynaptic terminal (Blackstad and Kjaerheim, 1961; Amaral and Dent, 1981; Chicurel and Harris, 1992), the spines are readily pinched of from the dendrite during synaptosome isolation, thus trapping the ribosomes and other contents of the spine cytoplasm. In principle, the procedure allows the complete recovery of all synaptic structures as part of the synaptosome.

Our analysis of the MF-CA3 synaptosome preparation indicates that this CNS synapse contains a restricted population of RNAs. A number of mRNAs coding for proteins known to be present in dendrites or astrocytic processes [e.g., mRNAs coding for the calcium/calmodulin-dependent kinase type II (CaM kinase II), and glial fibrillary acidic protcin (GFAP)] arc enriched in the MF-CA3 synaptosome preparation as compared to the total hippocampus. Other mRNAs, despite their abundance in the cells that form the synapse, are less prevalent or altogether absent from the MF-CA3 synaptosome (e.g., mRNAs coding for synaptophysin, and the GluRl glutamate receptor), indicating the restricted nature of the synaptic RNA. One particularly interesting species we have identified as concentrated in the synaptosomes is the small neural BC1 RNA, an apparently protein-associated RNA enriched in dendrites and suggested as being involved in dendritic pre- or posttranslational regulatory processes (Tiedge et al., 1991). These results constitute the first direct analysis of the specific RNA population present at a CNS synapse and suggest that the local protein synthesis necessary to maintain and modulate the strength of individual synapses may rely, at least in part, on mRNAs within the spine itself.

Portions of this rescarch have becn presented in abstract form (Chicurel et al., 1990, 1991).

\section{Materials and Methods}

Hippocampal MF-CA3 synaptosomal preparation. The detailed protocol for obtaining the MF-CA3 synaptosomal fraction has been described by Terrian et al. (1988). Briefly, the hippocampi of adult male Wistar rats were removed and manually homogenized in a $0.3 \mathrm{M}$ sucrose solution using modified custom-machined Dounce-type homogenizers (see Hajos et al., 1974). Manual disruption of the tissue with these particular homogenizers is required for the preservation of MF synaptosome integrity. In addition, all solutions used during the fractionation procedure contained $1 \mathrm{~mm} \mathrm{MgSO}_{4}$ to stabilize the large synaptosomal membranes. Homogenates were passed through a series of nylon filters, and high-speed centrifugations through sucrose were carried out to obtain the synaptosomal fractions.

Electron microscopy. EM analyses of the hippocampal MF-CA3 synapse (Chicurel and Harris, 1992) and the MF-CA3 synaptosomal preparation (Terrian et al., 1988) have been previously described. Briefly, preparation of tissue for EM involved perfusion through the heart with a $2 \%$ paraformaldehyde and $2.5 \%$ glutaraldehyde solution. Slices 400 $\mu \mathrm{m}$ thick were then soaked in an $\mathrm{OsO}_{4}$ and $\mathrm{K}_{4} \mathrm{Fe}(\mathrm{CN})_{6}$ solution. After immersion in a uranyl acetate solution followed by dehydration in graded alcohols, slices were embedded in Epon. Approximately $80 \mathrm{~nm}$ sections of hippocampal area CA3 stratum lucidum were stained with Reynolds' lead citrate and photographed at a JEOL 1200EX EM.

The synaptosome preparation was resuspended in a modified Karnovsky's fixative and sedimented in microcapillary tubes. Standard em- bedding and sectioning techniques were employed. A Hitachi HU-12A EM was used for photography.

$R N A$ isolation and Northern blot analysis. The Fast-Track kit (Invitrogen, San Diego, CA) was used for the isolation of RNA from MFCA3 synaptosomes and total rat hippocampi. This method includes extraction of RNA followed by selection of polyA ${ }^{+}$species using oligodT cellulose. RNA was denatured and electrophoresed in $1.5 \%$ formaldehyde-agarose gels and transferred to nitrocellulose (Schleicher and Schuell, Keene, NH) as has been previously described (Selden, 1989). Ethidium bromide was added directly to the sample prior to loading for subsequent visualization (Rosen and Villa-Komaroff, 1990). Equal amounts of synaptosomal and hippocampal RNA were electrophoresed as assessed by the densitometric analysis of the ethidium bromide stain. Except for the blot probed with the $\mathrm{BCl}$ specific oligonucleotide, all blots were prehybridized in $25 \mathrm{~mm} \mathrm{KPO}_{4}$, pH 7.4, $5 \times$ saline-sodium citrate (SSC), $5 \times$ Denhardt's solution, $50 \mu \mathrm{g} / \mathrm{ml}$ salmon sperm DNA, and $50 \%$ formamide and hybridized in the same solution at $42^{\circ} \mathrm{C}$ as described by Selden (1987). Except for the $\mathrm{BCl}$ oligonucleotide probe and the RC3 RNA probe (described below), all probes were labeled to a high specific activity by random hexamer priming of DNA synthesis in the presence of $\alpha-{ }^{32}$ P-dCTP (Feinberg and Vogelstein, 1983).

Probes specific for RNAs coding for rat synaptophysin [1.1 kilobase (kb) EcoRI in Bluescript; Buckley et al., 1987], the rat glutamate GluR 1 receptor (3 kb EcoRI-XhoI in Bluescript; Hollmann et al., 1989), chick $\alpha$-tubulin (1.4 kb PstI in pBR322; Cleveland et al., 1980), the rat calcium/calmodulin-dependent kinase type II $\alpha$-subunit $(1.3 \mathrm{~kb}$ EcoRI in pUC19; Ohmstede et al., 1989), mouse glial fibrillary acidic protein (2.5 kb EcoRI in pUC9; Lewis et al., 1984), rat tau protein (1.5 kb in pGEM-3; Kosik et al., 1989a), human MAP-2 (1 kb EcoRI in pBR322; Kosik et al., 1988), rat non-neural enolase (NNE) (1.8 kb BamHI in pCD; S. Forss-Petter, unpublished clone), human $\beta$-actin ( $1.8 \mathrm{~kb}$ BamHI in pCD; Leavitt et al., 1984), rat RC3 (1.5 kb BamHI in PHG327; Watson et al., 1990), and rat neuron-specific enolase (NSE) (2.4 kb in pCD; ForssPetter et al., 1986) were used. Except for the tau, BC1, and RC3 protein hybridizations, all filters were washed at a final stringency of $55^{\circ} \mathrm{C}$ in $0.2 \times \mathrm{SSC}, 0.1 \%$ SDS for $30 \mathrm{~min}$ and exposed to film with an intensifying screen at $-80^{\circ} \mathrm{C}$ for $6-24 \mathrm{hr}$. The tau blot was washed at a final stringency of $65^{\circ} \mathrm{C}$ in $0.2 \times \mathrm{SSC}, 0.1 \%$ SDS for $30 \mathrm{~min}$.

An RNA probe was used for the RC3 hybridization. The RC3 insert in PHG327 was first recloned into PGEM-7. After linearization of the plasmid, radiolabeled RNA was synthesized in the presence of ${ }^{32} \mathrm{P}$-CTP and T7 polymerase. The Riboprobe Gemini Kit (Promega, Madison, WI) was used for this purpose. Prehybridization and hybridization conditions were as described above. The blot was washed at a final stringency of $70^{\circ} \mathrm{C}$ in $0.2 \times \mathrm{SSC}, 0.1 \%$ SDS for $30 \mathrm{~min}$.

The labeling, hybridization, and washing conditions for the $\mathrm{BCl}$ Northern blot were as described in DeChiara and Brosius (1987). The probe consisted of a 60 -mer oligonucleotide complementary to the 60 $3^{\prime}$-most nucleotides in BC1 RNA (DeChiara and Brosius, 1987), which was end labeled with polynucleotide kinase.

All Northern blot analyses were repeated at least three times. A total of 36 synaptosome samples oblained from six different preparations were analyzed. Some of the results were obtained by reprobing of blots.

Quantification of the Northern blots was by densitometric analysis of autoradiographs on an LKB Ultroscan XL. For low-intensity signals, a Molecular Dynamics PhosphorImager was used to ensure linearity in the signal measurements.

\section{Results}

\section{Isolation of RNA from a defined CNS synapse}

The anatomical characteristics of the rat hippocampal MF-CA3 synapse and the fact that it contains a large number of postsynaptic ribosomes (Chicurel and Harris, 1989, 1992) suggested that this synapse might represent an ideal system for analyzing synapse-associated RNA. Furthermore, the synaptosomal preparation described by Terrian et al. (1988) provided a potential source from which to isolate and directly study the mRNA population present at the MF-CA3 synapse. By EM, this synaptosomal preparation is easily identified as enriched in MFCA3 synapses because of the distinctive size and complex morphology of the MF-CA3 synaptic components (Fig. 1). In addition, a modified Timm's sulfide-silver method for detecting 

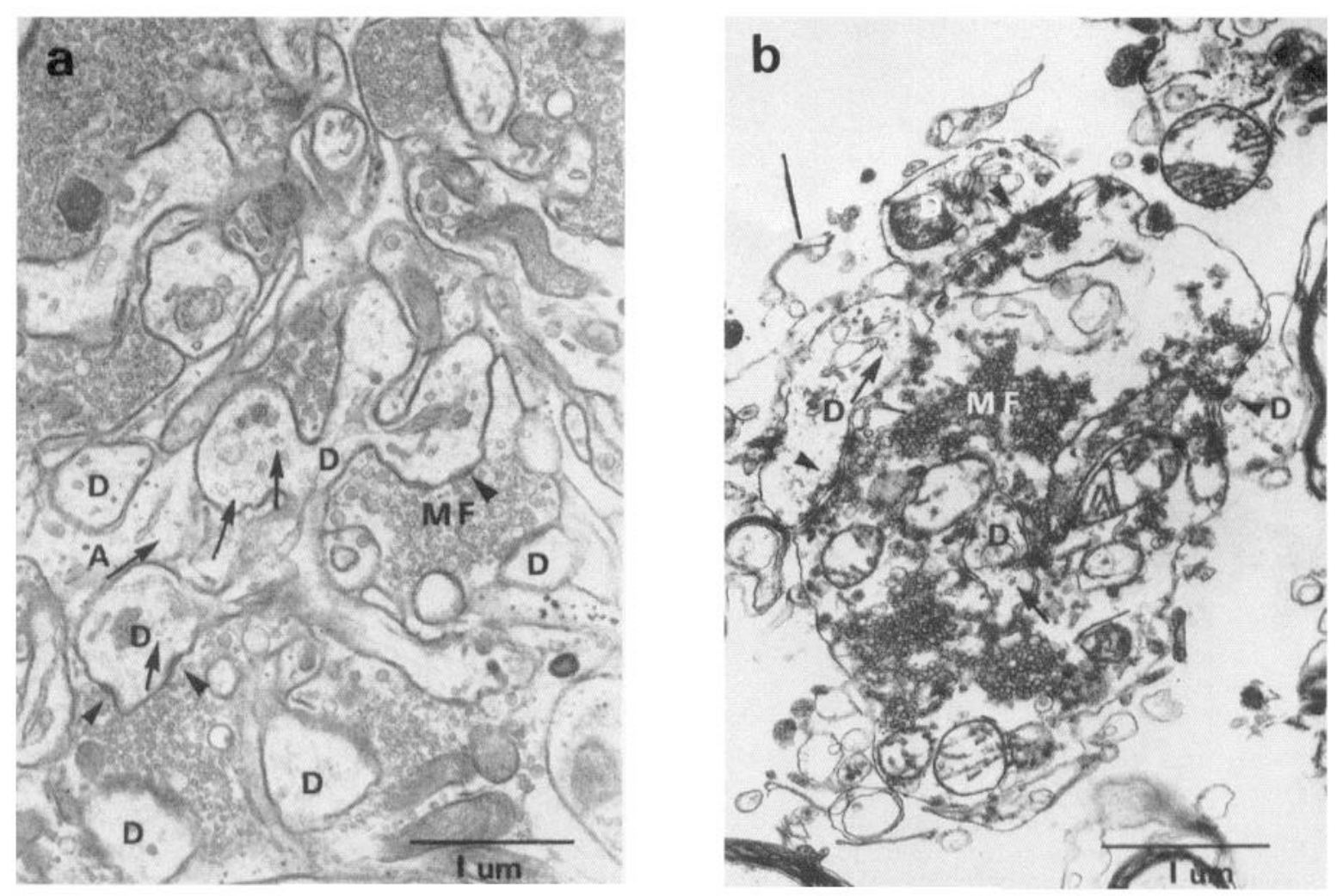

Figure 1. Electron micrographs of the MF-CA3 synapse. $a$, MF-CA3 synapse in stratum lucidum of hippocampal area CA3 (from Chicurel and Harris, 1992). $b$, MF-CA3 synaptosomal preparation. Arrows indicate ribosome clusters; arrowheads indicate PSDs. $M F$, MF boutons; $D$, dendritic spines; $A$, astrocyte processes.

zinc at the EM level has allowed the presence of MF terminals in the synaptosomes to be determined based on their unusually high and characteristic zinc content (Claiborne et al., 1989). Finally, the calcium-dependent release of transmitters has been extensively investigated (Terrian et al., 1988, 1989a,b, 1990; Conner-Kerr et al., 1992) and is consistent with the MF composition of the synaptosome preparation. In sum, three independent lines of evidence indicate a high degree of enrichment of MF-CA3 synaptosomes in this preparation.

EM analysis of the MF-CA3 synaptosome preparation showed that it contains the full complement of synaptic structures seen in vivo: the presynaptic MF terminals, the postsynaptic CA3 dendritic spines, and the associated astrocytic processes. More important, free polyribosomes are still present in the dendritic spines (Fig. $1 b$ ) and the astrocytic processes as is observed in vivo (Fig. $1 a$ ), indicating that it might be possible to isolate mRNA from the preparation. Indeed, we were able to isolate a nondegraded mRNA population from synaptosomes. Northern blot analysis was used to test the integrity of the RNA and to determine the relative abundances of RNA species of particular interest. Figures 2-4 show the results of these experiments. In all cases, polyA ${ }^{+}$RNA obtained from the synaptosomal preparation was compared to an equal amount of total hippocampal polyA + RNA. Except where noted, probes were obtained by labeling the entire cDNA plasmid clones of interest by primer extension of random hexamers.

\section{$M F-C A 3$ synaptosomes contain a restricted population of mRNAS}

The first set of probes used for Northern blot analysis were for RNAs that we considered highly unlikely to be present in the
MF-CA3 synaptosomes. For example, since both dendritic spines and fine astrocytic processes contain very little, if any, rough endoplasmic reticulum (RER) (Peters et al., 1991; Chicurel and Harris, 1992), mRNAs coding for proteins that require RER for their synthesis were tested.

Figure 2 (SYN) shows the Northern blot hybridization of synaptosomal RNA and total hippocampal RNA to a synaptophysin probe. Synaptophysin, a synaptic vesicle protein, is synthesized on RER and directed down the axon selectively. As expected, no mRNA for synaptophysin was detected in the synaptosomes. Yet this mRNA was abundant in RNA isolated from the entire hippocampus. It is interesting to note that strong in situ hybridization to synaptophysin mRNA has been observed specifically in hippocampal area CA3 (Marqueze-Pouey et al., 1991). (The filter labeled SYN in Fig. 2 was first successfully probed for the presence of actin mRNA, before being stripped and reprobed with synaptophysin, indicating that the absence of signal in the synaptosome lane cannot be attributed to a transfer artifact or degraded RNA.)

The absence of the mRNA for the GluR1/GluRA type of glutamate receptor in the MF-CA3 synaptosome preparation is shown in Figure 2 (GLU-R1). The cells involved in the MFCA3 synapse express high levels of the mRNA encoding the GluR 1/GluRA type of glutamate receptor, and the receptor is present in the MF-CA3 synapse. However, the GluR1/GluRA transmembrane protein, like synaptophysin, requires RER for its synthesis, and thus the presence of its mRNA would not be expected in the dendritic spines themselves or, therefore, in the synaptosome preparation. Indeed, as shown in the GLU-R1 lanes, the synaptosomes contain no detectable mRNA for the GluR1/GluRA receptor. [As with the synaptophysin filter, the 


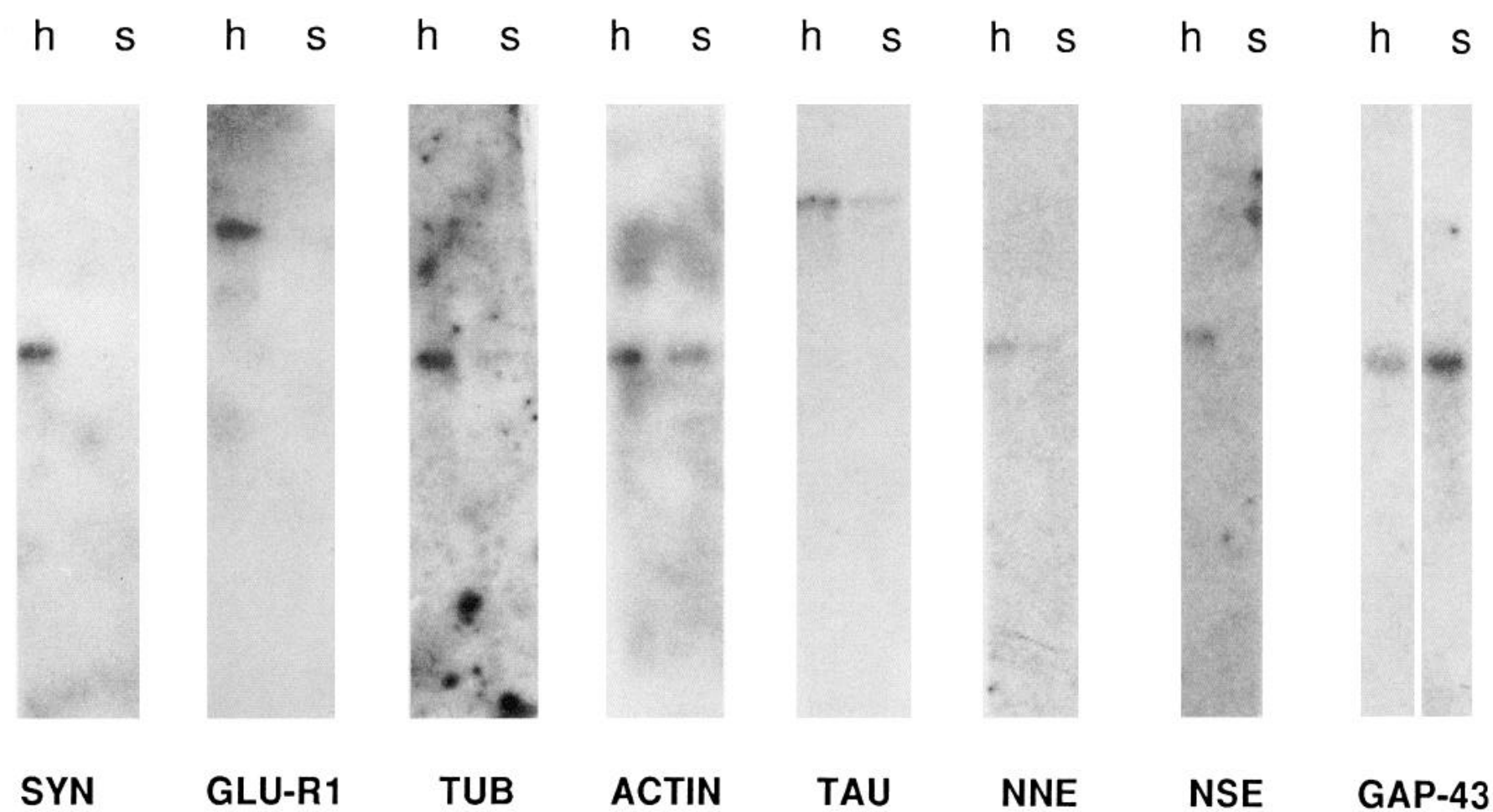

Figure 2. Northern blot analyses of mRNA species that were predicted to be present in very low abundance in the MF-CA3 synaptosome preparation. Results for each probe were obtained from at least three independent blots obtained from at least two different preparations. In some cases, filters were stripped and reprobed. Representative blots were selected for the figure. $h$, whole hippocampus polyA ${ }^{+}$RNA; $s$, synaptosomal polyA + RNA. The probes used for each pair of lanes are indicated: $S Y N$, synaptophysin; $G L U-R 1$, GluR1/GluRA glutamate receptor; TUB, $\alpha$-tubulin; $A C T I N, \beta$-actin; $T A U$, tau protein; $N N E$, non-neural enolase; $N S E$, neural-specific enolase; $G A P-43$, growth-associated protein 43 .

confidence of this result was supported by stripping the GLU$\mathrm{R} 1$ filter and reprobing with a CaM kinase II probe and an NNE probe, both of which identified their mRNAs in the synaptosome lane.]

Another three mRNAs that we expected to be expressed primarily in the cell body, from the in situ hybridization work of Garner et al. (1988), Bruckenstein et al. (1990), Kleiman et al. (1990), and Kosik et al. (1989a), encode $\alpha$-tubulin, $\beta$-actin, and tau. The lanes labeled TUB, ACTIN, and TAU in Figure 2 show, respectively, that $\alpha$-tubulin, $\beta$-actin, and tau mRNAs are located in only small amounts in MF-CA3 synaptosomes.

We also tested for the abundance of two mRNAs coding for metabolic enzymes in the synaptosomes: NNE and NSE. As expected from their "housekeeping" functions, both were present in lower amounts in the synaptosome as compared to total hippocampus (see lanes labeled NNE and NSE in Fig. 2).

Finally, we probed for the mRNA encoding the growth-associated protein GAP-43. As in the case of tubulin and actin, GAP-43 mRNA has been found by in situ hybridization to be apparently restricted to the cell soma (Bruckenstein et al., 1990; Kleiman et al., 1990). The GAP-43 lanes in Figure 2, however, show that GAP-43 mRNA is in fact present and even enriched in the MF-CA3 synaptosomes, suggesting a previously unsuspected role for GAP-43 in postsynaptic function.

\section{$M F-C A 3$ synaptosomes contain RNAs that have been previously found localized to neuronal and glial processes}

A second set of probes was used to test for the enrichment of RNAs whose intracellular location was previously studied by in situ hybridization and found to be in either dendritic or astrocytic processes: the microtubule-associated protein MAP2 , the CaM kinase II $\alpha$-subunit, GFAP, and neural BC1 RNA.

The abundance of MAP-2 mRNA in synaptosomes and whole hippocampus was assessed by dot and Northern blot analyses as shown in Figure 3. MAP-2 is a neuronal microtubule-associated protein found in dendrites and cell bodies, and MAP-2 mRNA has been shown to be present in dendrites (Garner et al., 1988; Bruckenstein et al., 1990; Kleiman et al., 1990). The MAP-2 mRNA is clearly present, though slightly less abundant, in synaptosomal RNA as compared to total hippocampal RNA.

Figure 3 also shows the results of Northern blot hybridization of RNA encoding the $\alpha$-subunit of CaM kinase II. CaM kinase II is highly concentrated at postsynaptic densities (PSDs) (Kennedy et al., 1983) and the $\alpha$-subunit mRNA has been shown, by in situ hybridization to tissue sections, to be present in hippocampal dendrites (Burgin et al., 1990). Our results demonstrate the presence of CaM kinase II $\alpha$-subunit mRNA in synaptosomes and at a higher level than in total hippocampal RNA.

A GFAP cDNA probe was used to analyze RNA in the GFAPlabeled lanes in Figure 3. GFAP is an astrocyte-specific intermediate-filament protein. As in the case of CaM kinase II $\alpha$-subunit, GFAP mRNA has been found by in situ hybridization to reside both in cellular processes and in the cell body (Sarthy et al., 1989; Trimmer et al., 1991). Our data show that GFAP mRNA is present at an approximately fivefold higher level in synaptosomes than in total hippocampus. This result likely reflects the presence of thin astrocytic processes containing ribosomes (and presumably mRNA) closely juxtaposed to the synapse, as can be seen in the electron micrograph of the intact tissue (Fig. 1a). 
Figure 3. Northern blot analyses of mRNA species of interest that are found in the MF-CA3 synaptosome preparation. As in Figure 2, results were obtained from at least three independent blots; a representative blot for each probe is shown. $h$, whole hippocampus polyA+ RNA; $s$, synaptosomal polyA ${ }^{+}$ RNA. MAP-2, MAP-2; CaM KII, CaM kinase II; $G F A P$, glial fibrillary acidic protein; $B C 1$, neural $\mathrm{BC} 1 ; R C 3, \mathrm{RC} 3$.

The other very abundant RNA we detected in the MF-CA3 synaptosomes is the neural $\mathrm{BC} 1 \mathrm{RNA}$. The $\mathrm{BC} 1$ lanes in Figure 3 show the result of probing total hippocampal and synaptosomal RNA populations with an oligonucleotide specific for neural $\mathrm{BC} 1 \mathrm{RNA} . \mathrm{BCl}$ is a small, noncoding polymerase III transcript, recently found to be particularly enriched in dendrites (Tiedge et al., 1991). The $5^{\prime}$ end of $\mathrm{BCl}$ is homologous to the ID repetitive sequence. An almost 10-fold enrichment for this RNA is observed in the synaptosome preparation. The probe used in this Northern blot was a 60-mer oligonucleotide complementary to the $3^{\prime}$ end of $\mathrm{BC} 1$. This region is unique to $\mathrm{BC} 1$ and does not include any sequence shared by the ID repetitive element.

We also probed the synaptosome RNA for the presence of RC3 mRNA. The RC3 protein (Watson et al., 1990) has recently been found highly enriched in dendritic spines (Watson et al., 1992). Since RC3 shares functional regions of homology with GAP-43, it has been proposed to be the dendritic counterpart of GAP-43 (Watson et al., 1992). We find RC3 mRNA to be present in the synaptosomes, although in lower amounts compared to the total hippocampus.

A summary of the data on the MF-CA3 synaptosome RNA composition as compared to total hippocampal RNA is shown in Figure 4. Densitometric and PhosphorImager analysis of Northern blots provides quantitative evidence that the synaptosome preparation is enriched in certain RNAs and depleted in others. Each bar represents the mean of at least three independent determinations.

\section{Discussion}

The multitude of synaptic contacts established by a typical CNS neuron suggests that some degree of local autonomy will underlie the maintenance and modulation of individual synapses. In many cases, changes in synaptic strengths are dependent on the level of activity at the particular synapse. The means by which an individual synapse maintains itself and also exhibits plastic-
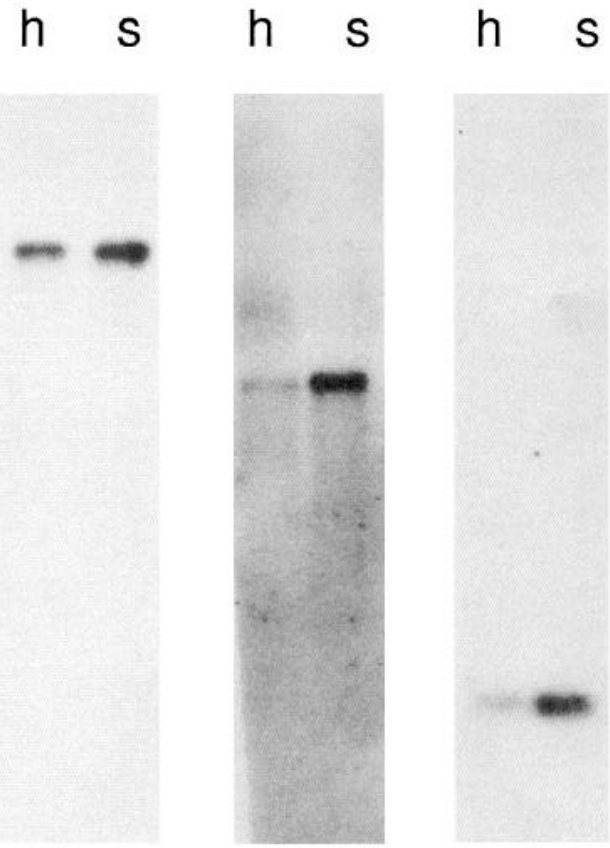

h s $S$

BC1

RC3

ity is likely to involve a number of mechanisms. In the short term, alterations in the activity of key proteins such as ion channels, neurotransmitter receptors, and protein kinases may be modulated by posttranslational modifications such as phosphorylation. Over longer periods, however, the constituents of the synapse must turn over and be replaced, and this requires new protein synthesis. Furthermore, the establishment of longterm changes in synaptic strength is likely to require new protein synthesis (Davis and Squire, 1984), which might usefully be restricted to the potentiated synapse. As previously discussed, several in situ hybridization studies have established the presence of mRNAs within the dendrites of neurons both in vivo and in cell culture.

Because in situ hybridization alone has insufficient spatial resolution to identify easily the synapse-specific mRNAs, which are those most likely involved in synapse maintenance and plasticity, we undertook to purify an enriched population of synaptic RNAs. To this end, we isolated hippocampal MF-CA3 synaptosomes that contain all of the components found at the synapse: the presynaptic boutons, the dendritic spines that synapse with these boutons, and the associated fine astrocytic processes. In general, presynaptic boutons and axons lack ribosomes (Peters et al., 1991; M. E. Chicurel and K. M. Harris, unpublished observations) as assessed by EM. Furthermore, axons from cells in culture have been shown to be incapable of protein synthesis (Vance et al., 1991). Thus, with the exception of mitochondrial sequences, in general, vertebrate axons contain very little if any mRNA (Bruckenstein et al., 1990; but see also Jirikowski et al., 1990; Mohr et al., 1991). We therefore expected that the isolation of polyA + RNA from this MF-CA3 synaptosome preparation would yield predominantly postsynaptic and astroglial process mRNA with some mitochondrial mRNA from the presynaptic bouton. That this favorable preparation for studying synaptic RNA reflects a general property of brain synapses is supported by the finding that protein synthesis can take place in dendrites (Torre and Steward, 1992) and isolated forebrain 
synaptosomes (Rao and Steward, 1991), indicating the presence of functional RNA and ribosomes.

\section{$M F-C A 3$ synaptosomes contain some mRNAs that code for synaptic proteins}

A variety of proteins are necessary for postsynaptic function. These include proteins responsible for the reception and transduction of synaptic inputs and proteins of the cytoskeleton that maintain the structure of the synapse. The proteins directly involved in the reception of the synaptic signal are found concentrated at the PSD, an electron-dense area found on the cytoplasmic face of the postsynaptic membrane. The major component of the PSD is CaM kinase II (or a CaM kinase II-related protein; see Wu et al., 1992), constituting 10-30\% of the total protein in this structure (Kennedy et al., 1983). CaM kinase II is a neuron-specific kinase (Hanley et al., 1987; Scholz et al., 1988) that appears to have a major role in the regulation of synaptic function. For instance, CaM kinase II has been implicated in the induction and maintenance of long-term potentiation (LTP) (see Kennedy, 1989) and, more recently, in learning and memory by studies of CaM kinase II knock-out mouse mutants (Silva et al., 1992a,b). Our finding of mRNA for CaM kinase II in the synaptosome preparation suggests that there is local synthesis of this protein in the MF-CA3 synapse. Such synthesis might be regulated by synaptic activity and thus contribute to changes in synaptic strength.

Another major group of postsynaptic proteins are those involved in forming and maintaining the cytoskeleton. Biophysical models indicate that spine shape may contribute importantly to the normal function and plasticity of synaptic activity (e.g., Rall, 1978; Koch and Poggio, 1983; Wilson, 1984; Brown et al., 1988; Harris and Stevens, 1988, 1989; Harris et al., 1992). The major regulatory cytoskeletal protein in dendrites is the microtubule-associated protein MAP-2. Interestingly, this protein is specifically enriched in brain PSDs, where it is apparently not associated with microtubules (Caceres et al., 1984). MAP-2 has also been found in the cytoplasm of cortical, cerebellar, and hippocampal dendritic spines, apparently associated with actin (Morales and Fifková, 1989). Unlike most dendritic spines, CA3 branched spines contain microtubules (Chicurel and Harris, 1992). Therefore, our finding of MAP-2 mRNA in MF-CA3 synaptosomes may reflect a role for the protein in determining the organization of dendritic spine microtubules, actin filaments, and/or PSD function.

A precedent for RNA localization in response to a need for local protein synthesis associated with cell shape is provided by spreading fibroblasts and by endothelial cells responding to cellular injury. In each case, actin mRNA localizes to the plasma membrane and the regions of moving cytoplasm, precisely where it is most needed (Hoock et al., 1991; Sundell and Singer, 1991). Although it is likely that the cell synthesizes some proteins in the soma and transports them to the processes, it has been suggested that the synthesis of such complex subcellular structures as the cytoskeleton may require that the translation of the individual components be coupled to their assembly (Isaacs and Fulton, 1987), in a manner analogous to the cotranslational requirement of the transmembrane assembly of membranespanning proteins. If the PSD is assembled in this cooperative manner, it may similarly depend on local synthesis of its components (Palacios-Pru et al., 1988; Rao and Steward, 1991). The presence of MAP-2 RNA together with CaM kinase II RNA in the MF-CA3 synaptosome is consistent with this hypothesis.

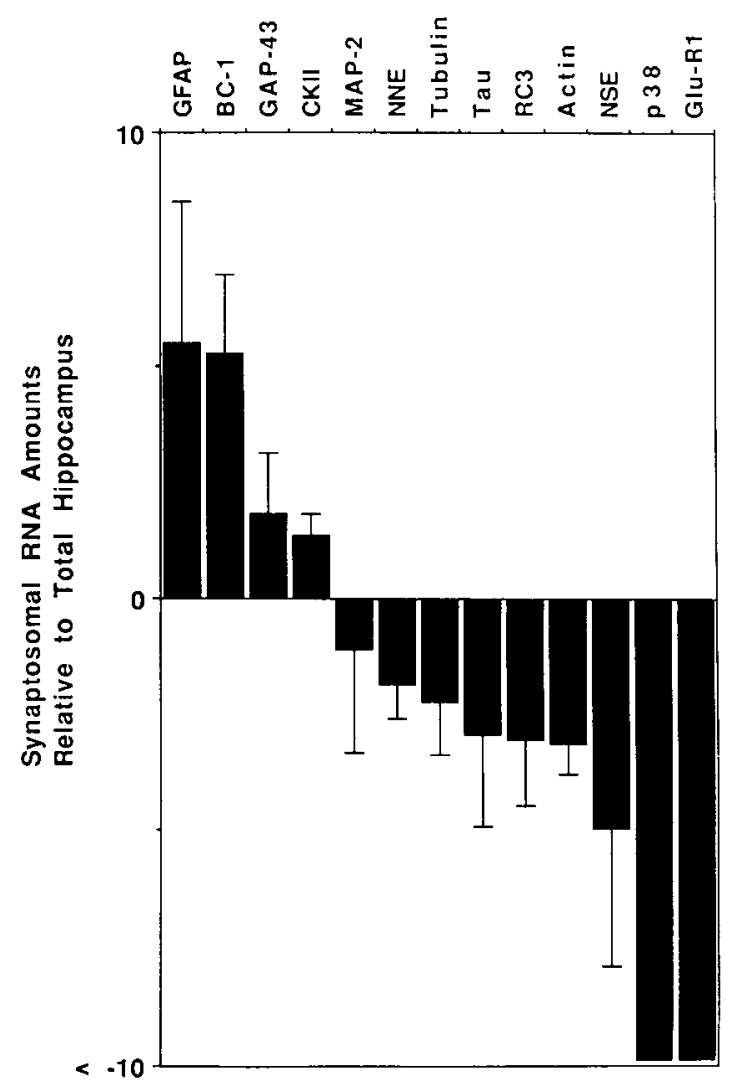

Figure 4. Summary of MF-CA3 synaptosome RNA composition. Data from analysis of Northern blots loaded with equal amounts of hippocampal and synaptosomal RNA is shown. Autoradiographic signals. were measured on a densitometer (for low-intensity signals a PhosphorImager was used). The abundance of individual species in the synaptosomes is shown presented relative to total hippocampus. The values on the $y$-axis represent the $n$-fold enrichment in the synaptosome as compared to total hippocampus, such that a value of 10 represents the presence of a 10-fold enrichment in the synaptosome versus total hippocampus, and a value of -8 represents the presence of an eightfold lesser amount in the synaptosome versus total hippocampus. Each bar and its associated standard error were obtained from an average of at least three different assays.

If local protein synthesis is involved in regulating or mediating synaptic activity, then a system to link these two processes must exist. Calcium has been recognized as a possible modulator of translation (Brostrom and Brostrom, 1990). Thus, we might expect that the dramatic increase in calcium levels known to occur in dendrites, and in dendritic spines in particular, following synaptic stimulation (Guthrie et al., 1991; Muller and Connor, 1991) could also regulate local protein synthesis and provide the link between synaptic activity and the synthesis of synaptic proteins. In this regard, Weiler and Greenough (1991) have recently shown that depolarization-related changes, including changes in calcium concentrations, can affect the association of mRNA with polyribosomal complexes in synaptosomes.

Another protein suspected to be involved in synaptic plasticity is the growth-associated protein GAP-43. Although its specific function has not been determined, its presence has been correlated with development, regeneration, and plasticity in the adult nervous system. Until recently, GAP-43 was thought to be restricted to cell bodies and axons and to be particularly enriched in nerve terminals. Recent evidence, however, indicates that GAP-43 is also found in dendrites and, more specif- 
ically, in the tips of dendritic spines (DiFiglia et al., 1990). Therefore, our finding of GAP-43 mRNA in the MF-CA3 synaptosome lends further support to the hypothesis that local protein synthesis contributes to the regulation of plasticity at the synapse. GAP-43 protein levels have been found to be regulated at a posttranscriptional level (Benowitz and Perrone-Bizzozero, 1991), which is consistent with a possible role for localized control of GAP-43 translation. It is unlikely that the GAP-43 RNA in the MF-CA3 preparation results from contamination from the cell bodies because other RNAs that should be restricted to cell bodies (RER-associated mRNAs) are found to be completely absent from the preparation. Furthermore, since GAP-43 mRNA is not found in the granule cells that give rise to the MFs (Meberg and Routtenberg, 1991) and is present in large amounts in the CA3 cells that give rise to the dendritic spines, the GAP-43 mRNA in the MF-CA3 synaptosomes is likely derived from the postsynaptic dendritic spine. Interestingly, GAP-43 mRNA has not been observed in dendrites of cultured neurons by in situ hybridization (Bruckenstein et al., 1990; Kleiman et al., 1990). Together these data appear to indicate that GAP-43 mRNA is concentrated at the synapse, in the dendritic spines, but is present only in very low amounts in dendrite shafts. A similar synaptic localization in the stratum lucidum may also apply to BC1 RNA, as discussed below.

Since GAP-43 mRNA was detected in the synaptosomes, we decided to test for the presence of the homologous, but predominantly dendritic, mRNA coding for the RC3 protein. RC3 mRNA was found in only small amounts in the synaptosome as compared to total hippocampus. However, its presence is of interest since $\mathrm{RC} 3$ has been recently postulated as a "third messenger" substrate in the postsynaptic transduction pathway, and RC3 protein is found highly concentrated in dendritic spines (Watson et al., 1992). Like GAP-43, RC3 is a protein kinase C substrate and binds calmodulin (Watson et al., 1990). Recent evidence suggests that RC3 may function by regulating calcium ion levels in dendritic spines (Coulter et al., 1992).

The synapse consists not only of the postsynaptic dendritic spine and the presynaptic bouton, but also of fine astrocytic processes surrounding and intermingling with the neuronal elements. Thesc astrocytic proccsses arc thought to carry out a number of processes important for synaptic function. Not only do astrocytes perform support functions, for instance, serving to "buffer" the extracellular potassium concentration around neurons, but Cornell-Bell et al. (1990) have recently shown that astrocytes exhibit calcium waves in response to glutamate and neuronal activity (Dani et al., 1992), suggesting that they may play a direct role in modulating synaptic activity through changes in local calcium concentrations. The involvement of astrocytes in synaptic functions is further supported by the findings of Wenzel et al. (1991), who have shown that there is an increase in the apposition of the fine astrocytic processes to the synaptic components-synaptic clefts, presynaptic terminals, and dendritic spines-in dentate gyrus neuropil after LTP, suggesting an important involvement of these processes in synaptic physiology and plasticity. Furthermore, it has been found recently that levels of the key structural mRNA unique to astrocytcs, that encoding GFAP, can change in response to changes in synaptic activity (Steward et al., 1990). Two groups (Sarthy et al., 1989; Trimmer et al., 1991) have observed GFAP mRNA in astrocytic processes by in situ hybridization. Given the close association of astrocytic processes with the neuronal elements in the synaptosome preparation from the MF-CA3 synapse, we would expect that astrocytic mRNAs important for synaptic function might be localized in these astrocytic processes just as certain neuronal RNAs are localized in the adjacent neuronal processes. Indeed, we find a high level of mRNA encoding GFAP in this synaptosome preparation. This result is made particularly significant by our EM observations, which indicate the presence, but not an abundance, of astrocytic processes in the synaptosomal preparations. Thus, the GFAP mRNA must be very highly concentrated in these synaptic astrocytic processes.

Because of the close proximity of the MF-CA3 synapse to the cell body of the CA3 pyramidal cell (10-145 $\mu \mathrm{m}$; Johnston and Brown, 1983), the synaptosome might contain a certain amount of "spillover" mRNAs located primarily in the cell body. The small amounts of tau, tubulin, NSE (a neural-specific isoform of the glycolytic enzyme enolase), and actin in the synaptosome preparation and the previous in situ hybridization studies of tau, tubulin, and actin RNA (Garner et al,, 1988; Kosik et al., 1989a; Bruckenstein et al., 1990; Kleiman et al., 1990) support this interpretation. In addition, one cannot exclude the possibility that synaptosomal MAP-2 and RC3 RNAs, both coding for synaptic proteins but present in relatively low amounts in synaptosomes, are also the result of cell body RNA "spillover."

\section{Synaptosomes lack RER-associated mRNAs}

The biological significance of the fact that mRNAs translated on RER are absent from the dendritic spines and astrocytic processes in the synaptosome preparation may appear paradoxical since many of the proteins that play key roles in synaptic function (e.g., transmitter receptors and ion channels) require RER for their synthesis. The absence of the mRNA for the GluR1/GluRA type of glutamate receptor in the synaptosomes is particularly interesting. GluR $1 /$ GluRA receptors are abundant throughout the hippocampus (Hollmann et al., 1989) and, in particular, in the dendrites of CA3 cells in the stratum lucidum (Rogers et al., 1991), the neuropil layer where the MFCA3 synapse is located. In addition, in situ hybridization indicates abundant GluR1/GluRA receptor mRNA in the dentate gyrus and CA3 pyramidal cell body layers (Keinänen et al., 1990 ), indicating that the cells involved in the MF-CA3 synapse express high levels of this mRNA.

A possible explanation for the lack of RER-associated mRNAs is that the cytoplasmic volume of both fine astrocytic processes and dendritic spines is not large enough to contain the complete machinery required for synthesis of membrane and secretory proteins (e.g., RER and Golgi apparatus). As previously mentioned, many studies have indicated the connection between dendritic spine shape and function; a change in spine shape to accommodate secretory and transmembrane protein synthetic machinery might be expected to interfere with function. Nevertheless, RER-associated mRNAs coding for synaptic proteins can still be positioned locally, in the nearby dendritic shaft. Indeed, Steward and Reeves (1988) have found polyribosomes to be associated with membranous cisternae at the bases of spines in the dentate gyrus and area CAl in the hippocampus, suggesting the local synthesis of transmembrane and secretory products.

\section{Neural BC1 RNA is highly concentrated in spine-containing synaptosomes}

Our results indicate that a very prominent component of the $\mathrm{MF}-\mathrm{CA} 3$ synaptosome RNA population is the neural BC1 RNA. 
BCI RNA is a noncoding polymerase III transcript of 152 bases that has recently been found by in situ hybridization to be particularly enriched in dendrites (Tiedge et al., 1991). In area CA3 of the hippocampus, $\mathrm{BCl}$ is found abundantly in stratum pyramidale, the layer that contains the somata and proximal dendrites of the pyramidal cells, and in the distal parts of apical dendrites. However, in stratum lucidum, the area containing the MF boutons and branched dendritic spines, $\mathrm{BC} 1$ is found at very low, but detectable, levels by in situ hybridization. It was therefore somewhat surprising to find an abundance of $\mathrm{BC} 1$ in our MF-CA3 preparation that is derived from the stratum lucidum. As suggested above for GAP-43, a likely and interesting explanation is that $\mathrm{BCl}$ in stratum lucidum is low in dendrite shafts but highly concentrated in the dendritic spinesa strong indication of its potential importance in synaptic function. Thus, the low overall level of $\mathrm{BCl}$ RNA in this region as assessed by in situ hybridization of tissue sections may reflect the fact that the overall synaptic density in stratum lucidum is probably lower than in other neuropil regions: although the number of PSDs per unit length of dendrite is somewhat larger in stratum lucidum than in other neuropil layers (3.5 PSDs $/ \mu \mathrm{m}$ vs 2 PSDs $/ \mu \mathrm{m}$ ), the total number of dendritic branches per unit volume is much lower than at more distal areas [10 branches per neuron vs 30 branches per neuron (Fitch et al., 1989)] and thus the overall density of synapses is lower. Taken together with the in situ hybridization results, these results argue that $\mathrm{BCl}$ is specifically concentrated at synapses.

The function of $\mathrm{BCl}$ RNA is unknown at present, but it appears to form part of a high-molecular-weight ribonucleoprotein particle (RNP) and thus has been suggested to be involved in dendritic pre- or posttranslational regulatory processcs (Kobayashi et al., 1991; Tiedge et al., 1991). The abundance of $\mathrm{BC} 1$ detected in the MF-CA3 synaptosome suggests that this RNP has a specific role at the synapse, possibly in the regulation of synaptic domain-specific protein synthesis. Alternatively, BC1 RNA may be involved in other processes, such as the targeting of RNA from the cell body to synapses.

\section{The mechanism(s) underlying synaptic RNA localization, sorting, and local translational regulation}

Although only recently thought to apply to mRNA within the cytoplasm, RNA targeting is, in fact, a well-established cellular function. The most universal case is the retention of immature, unspliced RNA (i.e., heterogeneous nuclear RNA) in the nucleus until it has been processed to yield cytoplasmic mRNA. Apparently, protein and RNA factors recognize introns in unprocessed RNA inolecules, forming a complex that prevents the RNA from moving into the cytoplasm (for review, see Nigg et al., 1991). In addition, certain mRNAs are differentially segregated within Drosophila embryos and Xenopus oocytes, and help establish initial gradients of expression during development. Some of the mechanisms underlying this localization are beginning to be elucidated (MacDonald and Struhl, 1988; Yisraeli et al., 1990; Davis and Ish-Horowicz, 1991; Mowry and Melton, 1992). In some cases, it has been shown that specific scquences in the $3^{\prime}$ untranslated regions (UTRs) of the mRNAs are required for their localization. In addition, in more differentiated cells such as spreading fibroblasts, actin has been found to localize to the cell periphery (Sundell and Singer, 1990, 1991). A sequence responsible for actin mRNA binding to the cytoskeleton has also been identified at the 3' UTR (J. Pachter, personal communication).
The 3' UTRs of many mRNAs are often more conserved in evolution than the coding regions (Yaffe et al., 1985), and may similarly provide recognition sites for RNA transport and/or anchoring in neurons. If, as previously suggested, translational control occurs locally at synaptic regions, then it is reasonable to expect the presence of specific translational regulators at the synapse, and 3' UTRs of synaptic RNAs may serve as targets for such regulation. Translational control of some RNAs is already known to occur by the interaction of proteins with $3^{\prime}$ UTRs (for review, see Jackson and Standart, 1990). It will be of interest to search for such regulators in the synapse.

\section{Conclusions}

In sum, our results suggest that the local protein synthesis necessary to maintain and modulate the strength of individual synapses utilizes mRNAs within the dendritic spines themselves. These transcripts encode proteins involved in spine shape and second messenger systems. Other mRNAs, such as neurotransmitter receptors and ion channels, are apparently absent from the spines themselves but may be associated with the RER in the dendritic shaft at the base of the spine. The MF-CA3 synaptosome preparation affords the possibility of manipulating the synapse in vivo prior to RNA analysis and directly assessing the contribution local $\mathrm{mRNA}$ regulation makes to synaptic plasticity.

Rao and Steward (in press) have independently obtained similar results from a preparation of forebrain synaptosomes.

\section{References}

Amaral DG, Dent JA (1981) Development of the mossy fibers of the dentate gyrus: I. A light- and electron-microscopic study of the mossy fibers and their expansions. J Comp Neurol 195:51-86.

Benowitz LI, Perrone-Bizzozero NI (1991) The relationship of GAP43 to the development and plasticity of synaptic connections. Ann NY Acad Sci 627:58-74.

Blackstad TW, Kjaerheim $\AA$ (1961) Special axo-dendritic synapses in the hippocampal cortex: electron and light microscopic studies in the layer of mossy fibers. J Comp Neurol 11:133-146.

Brostrom CO, Brostrom MA (1990) Calcium-dependent regulation of protein synthesis in intact mammalian cells. Annu Rev Physiol 52: $577-590$.

Brown TH, Chang VC, Ganong AH, Keenan CL, Kelso SR (1988) Biophysical properties of dendrites and spines that may control the induction and expression of long-term synaptic potentiation. Neurol Neurobiol 35:201-264.

Bruckenstein DA, Lein PJ, Higgins D, Fremeau RT (1990) Distinct spatial localization of specific mRNAs in cultured sympathetic neurons. Neuron 5:809-819.

Buckley KM, Floor E, Kelly RB (1987) Cloning and sequence analysis of cDNA encoding p38, a major synaptic vesicle protein. J Cell Biol 105:2447-2456.

Burgin KW, Waxham MN, Rickling S, Westgate SA, Mobely WC, Kelly PT (1990) In situ hybridization: histochemistry of $\mathrm{Ca}^{2+} /$ calmodulindependent protein kinase in developing rat brain. J Neurosci 10:17881798 .

Caceres A, Binder LI, Payne MR, Bender P, Rebhun L, Steward O (1984) Differential subcellular localization of tubulin and the microtubule-associatcd protcin MAP-2 in brain tissuc as revealed by immunocytochemistry with monoclonal hybridoma antibodies. J Neurosci 4:394-410.

Chicurel ME, Harris KM (1989) Serial electron microscopy of CA3 dendritic spines synapsing with mossy fibers of rat hippocampus. Soc Neurosci Abstr 15:256.

Chicurel ME, Harris KM (1992) Three dimensional structure and composition of $\mathrm{CA} 3$ branched spines and their synaptic relationships with mossy fiber boutons in the rat hippocampus. J Comp Neurol 325:169-182.

Chicurel ME, Terrian DM, Potter H (1990) Subcellular localization 
of mRNA: isolation and characterization of mRNA from an enriched preparation of hippocampal dendritic spines. Soc Neurosci Abstr 16: 354.

Chicurel ME, Terrian DM, Harris KM, Potter H (1991) Localization of RNA at synapses: analysis of a preparation enriched in hippocampal dendritic spines. Soc Neurosci Abstr 17:379.

Claiborne BJ, Rea MA, Terrian DM (1989) Detection of zinc in isolated nerve terminals using a modified Timm's sulfide-silver method. J Neurosci Methods 30:17-22.

Cleveland D, Lopata MA, MacDonald RJ, Cowan N, Kutter WJ, Kirschner MW (1980) Number and evolutionary conservation of $\alpha$ and $\beta$-tubulin and cytoplasmic $\beta$ - and $\gamma$-actin genes using specific cloned cDNA probes. Cell 20:95-105.

Colman DR, Kreibich G, Frey AB, Sabitini DD (1982) Synthesis and incorporation of myelin polypeptides into CNS myelin. J Cell Biol 95:598-608.

Conner-Kerr TA, Simmons DR, Peterson GM, Zetts OA, Terrian DM (1992) Evidence for co-release of dynorphin and glutamate from rat hippocampal mossy fiber terminals. Trans Am Soc Neurochem 23: 222.

Cornell-Bell AH, Finkbeiner SM, Cooper MS, Smith SJ (1990) Glutamate induces calcium waves in cultured astrocytes: long range glial signaling. Science 247:470-473.

Coulter PM II, Cohen RW, Margulies JE, Watson JB (1992) Assembly and PKC-phosphorylation of RC3 (neurogranin) in rat brain synaptosomes and voltage-clamped Xenopus oocytes. Soc Neurosci Abstr $18: 1345$.

Dani JW, Chernjavsky A, Smith SJ (1992) Neuronal activity triggers calcium waves in hippocampal astrocyte networks. Neuron 8:429440.

Davis HP, Squire LR (1984) Protein synthesis and memory: a review. Psychol Bull 96:518-559.

Davis I, Ish-Horowicz D (1991) Apical localization of pair-rule transcripts requires $3^{\prime}$ sequences and limits protein diffusion in the Drosophila blastoderm embryo. Cell 67:927-940.

DeChiara TM, Brosius J (1987) Neural BC1 RNA: cDNA clones reveal nonrepetitive sequence content. Proc Natl Acad Sci USA 84:26242628.

DiFiglia M, Roberts RC, Benowitz LI (1990) Immunoreactive GAP43 in the neuropil of adult rat neostriatum: localization in unmyelinated fibers, axon terminals, and dendritic spines. J Comp Neurol 302: 992-1001.

Feinberg AP, Vogelstein B (1983) A technique for radiolabelling DNA restriction endonuclease fragments to high specific activity. Anal Biochem $132: 6$

Feinberg AP, Vogelstein B (1984) Addendum: a technique for radiolabelling DNA restriction endonuclease fragments to high specific activity. Anal Biochem 137:266.

Fitch JM, Juraska JM, Washington LW (1989) The dendritic morphology of pyramidal neurons in the rat hippocampal CA3 area. I. Cell types. Brain Res 479:105-114.

Forss-Petter S, Danielson P, Sutcliffe JG (1986) Neuron-specific enolase: complete structure of rat mRNA, multiple transcriptional start sites, and evidence suggesting post-transcriptional control. J Neurosci Res 16:141-156.

Garner CC, Tucker RP, Matus A (1988) Selective localization of messenger RNA for cytoskeletal protein MAP2 in dendrites. Nature 336 674-677.

Gillespie CS, Trapp BD, Colman DR, Brophy PJ (1990) Distribution of myelin basic protein and $P_{2}$ mRNAs in rabbit spinal cord oligodendrocytes. J Neurochem 54:1556-1561.

Gould RM, Mattingly G (1990) Regional localization of RNA and protein metabolism in Schwann cells in vivo. J Neurocytol 19:285301.

Guthrie PB, Segal M, Kater SB (1991) Independent regulation of calcium revealed by imaging dendritic spines. Nature 354:76-80.

Hajos F, Tapia R, Wilkin G, Johnson AL, Balazs R (1974) Subcellular fractionation of rat cerebellum: an electron microscopic and biochemical investigation. I. Preservation of large fragments of the cerebellar glomeruli. Brain Res 70:261-279.

Hanley RM, Means AR, Ono T, Kemp BE, Burgin KE, Waxham N, Kelly PT (1987) Functional analysis of a complementary DNA for the 50-kilodalton subunit of calmodulin kinase II. Science 237:294 297.

Harris KM, Stevens JK (1988) Dendritic spines of rat cerebellar Pur- kinje cells: serial electron microscopy with reference to their biophysical characteristics. J Neurosci 8:4455-4469.

Harris KM, Stevens JK (1989) Dendritic spines of CAl pyramidal cells in the rat hippocampus: serial electron microscopy with reference to their biophysical characteristics. J Neurosci 9:2982-2997.

Harris KM, Jensen FE, Tsao B (1992) Three-dimensional structure of dendritic spines and synapses in rat hippocampus (CA1) at postnatal day 15 and adult ages: implications for the maturation of synaptic physiology and long-term potentiation. J Neurosci 12:26852705.

Hollmann M, O'Shea-Greenfield A, Rogers SW, Heinemann S (1989) Cloning by functional expression of a member of the glutamate receptor family. Nature 342:643-648.

Hoock TC, Newcomb PM, Herman IM (1991) $\beta$-actin and its mRNA are localized at the plasma membrane and the regions of moving cytoplasm during the cellular response to injury. J Cell Biol 112:653664.

Isaacs WB, Fulton AB (1987) Cotranslational assembly of myosin heavy chain in developing cultured skeletal muscle. Proc Natl Acad Sci USA 84:6174-6178.

Jackson RJ, Standart N (1990) Do the poly(A) tail and 3' untranslated region control mRNA translation? Cell 62:15-24.

Jirikowski GF, Sanna PP, Bloom FE (1990) mRNA coding for oxytocin is present in axons of the hypothalamo-neurohypophysial tract. Proc Natl Acad Sci USA 87:7400-7404.

Johnston D, Brown TH (1983) Interpretation of voltage-clamp measurements in hippocampal neurons. J Neurophysiol 50:464-486.

Keinänen K, Wisden W, Sommer B, Werner P, Herb A, Verdoorn TA, Sakmann B, Seeburg PH (1990) A family of AMPA-selective glutamate receptors. Science 249:556-560.

Kennedy MB (1989) Regulation of synaptic transmission in the central nervous system: long-term potentiation. Cell 59:777-787.

Kennedy MB, Bennett MK, Erondu NE (1983) Biochemical and immunochemical evidence that the "major postsynaptic density protein" is a subunit of a calmodulin-dependent protein kinase. Proc Natl Acad Sci USA 80:7357-7361.

Kleiman R, Banker G, Steward O (1990) Differential subcellular localization of particular mRNAs in hippocampal neurons in culture. Neuron 5:821-830.

Kobayashi S, Goto S, Anzai K (1991) Brain-specific small RNA transcript of the identifier sequences is present as a $10 \mathrm{~S}$ ribonucleoprotein particle. J Biol Chem 266:4726-4730.

Koch C, Puggio T (1983) A theoretical analysis of electrical properties of spines. Proc R Soc Lond [Biol] 218:455-477.

Kosik KS, Orecchio LD, Bakalis S, Duffy L, Neve RL (1988) Partial sequence of MAP2 in the region of a shared epitope with Alzheimer neurofibrillary tangles. J Neurochem 51:587-598.

Kosik KS, Crandall JE, Mufson EJ, Neve RL (1989a) Tau in situ hybridization in normal and Alzheimer brain: localization in the somatodendritic compartment. Ann Neurol 26:352-361.

Kosik KS, Orecchio LD, Bakalis S, Neve RL (1989b) Developmentally regulated expression of specific tau sequences. Neuron 2:1389-1397.

Leavitt J, Gunning P, Porreca P, Ng S-Y, Lin C-S, Kedes L (1984) Molecular cloning and characterization of mutant and wild-type human $\beta$-actin genes. Mol Cell Biol 4:1961-1969.

Lewis SA, Balcarek JM, Krek V, Shelanski M, Cowan NJ (1984) Sequence of a cDNA clone encoding mouse glial fibrillary acidic protein: structural conservation of intermediate filaments. Proc Natl Acad Sci USA 81:2743-2746.

MacDonald PM, Struhl G (1988) Cis-acting sequences responsible for anterior localization of bicoid mRNA in Drosophila embryos. Nature 336:595-598.

Marqueze-Pouey B, Wisden W, Malosio ML, Betz H (1991) Differential expression of synaptophysin and synaptoporin mRNAs in the postnatal rat central nervous system. J Neurosci 11:3388-3397.

Meberg PJ, Routtenberg A (1991) Selective expression of protein F1/ (GAP-43) mRNA in pyramidal but not granule cells of the hippocampus. Neuroscience 45:721-733.

Mohr E, Fehr S, Richter D (1991) Axonal transport of neuropeptide encoding mRNAs within the hypothalamo-hypophyseal tract of rats. EMBO J 10:2419-2424

Morales M. Fifková E (1989) In situ localization of myosin and actin in dendritic spincs with the immunogold technique. J Comp Neurol 279:666-674.

Mowry KL, Melton DA (1992) Vegetal messenger RNA localization 
directed by a 340 -nt RNA sequence element in Xenopus oocytes. Science 255:991-994.

Muller W, Connor JA (1991) Dendritic spines as individual neuronal compartments for synaptic $\mathrm{Ca}^{++}$responses. Nature 354:73-76.

Nigg EA, Baeuerle PA, Lürhmann R (1991) Nuclear import-export: in search of signals and mechanisms. Cell 66:15-22.

Ohmstede C-A, Jensen KF, Sahyoun NE (1989) $\mathrm{Ca}^{++} /$calmodulindependent protein kinase enriched in cerebellar granule cells. J Biol Chem 264:5866-5875.

Palacios-Pru E, Miranda-Contreras L, Mendoza RV, Zambrano E (1988) Dendritic RNA and postsynaptic density formation in chick cercbellar synaptogenesis. Neuroscience 24:111-118.

Peters A, Palay SL, Webster H deF (1991) The fine structure of the nervous system: the neurons and supporting cells, $3 \mathrm{~d}$ ed. Philadelphia: Saunders.

Phillips LL, Steward O (1990) Increases in mRNA for cytoskeletal proteins in the denervated neuropil of the dentate gyrus: an in situ hybridization study using riboprobes for $\beta$-actin and $\beta$-tubulin. Mol Brain Res 8:249-257

Rall W (1978) Dendritic spines and synaptic potency. In: Studies in neurophysiology (McIntyre AK, Porter K, eds), pp 203-209. Cambridge: Cambridge UP.

Rao A, Steward O (1991) Evidence that protein constituents of postsynaptic membrane specializations are locally synthesized: analysis of protein synthesis within synaptosomes. J Neurosci 11:2881-2895.

Rao A, Steward O (1993) Evaluation of RNAs present in synaptodendrosomes: dendritic, glial, and cell contribution. J Neurochem, in press.

Rogers SW, Hughes TE, Hollmann M, Gasic GP, Deneris ES, Heineman $S$ (1991) The characterization and localization of the glutamate receptor subunit GluR1 in the rat brain. J Neurosci 11:2713-2724.

Rosen KM, Villa-Komaroff L (1990) An alternative method for the visualization of RNA in formaldehyde agarose gels. Focus 12:23-24.

Sarthy PV, Fu M, Huang J (1989) Subcellular localization of an intermediate filament protein and its mRNA in glial cells. Mol Cell Biol 9:4556-4559.

Scholz WK, Baitinger C, Schulman H, Kelly PT (1988) Developmental changes in $\mathrm{Ca}^{++} /$calmodulin-dependent protein kinase II in cultures of hippocampal pyramidal neurons and astrocytes. J Neurosci 8:10391051 .

Selden RF (1987) Analysis of RNA by Northern hybridization. In: Current protocols in molecular biology (Ausubel FM, Brent R, Kingston RE, Moore DD, Seidman JG, Smith JA, Struhl K, eds), pp 4.9.14.9.8. New York: Wiley.

Selden RF (1989) Southern blotting and hybridization. In: Current protocols in molecular biology (Ausubel FM, Brent R, Kingston RE, Moore DD, Seidman JG, Smith JA, Struhl K, eds), pp 2.9.1-2.9.10. New York: Wiley.

Silva AJ, Stevens CF, Tonegawa S, Wang Y (1992a) Deficient hippocampal long-term potentiation in a calcium-calmodulin kinase II mutant mice. Science 257:201-206.

Silva AJ, Paylor R, Wehner JM, Tonegawa S (1992b) Impaired spatial learning in a-calcium-calmodulin kinase II mutant mice. Science 257: 206-211.

Steward O, Banker GA (1992) Getting the message from the gene to the synapse: sorting and intracellular transport of RNA in neurons. Trends Neurosci 15(5):180-186.

Steward O, Levy WB (1982) Preferential localization of polyribosomes under the base of dendritic spines in granule cells of the dentate gyrus. J Neurosci 2:284-291.

Steward O, Reeves TM (1988) Protein-synthetic machinery beneath postsynaptic sites on CNS neurons: association between polyribosomes and other organelles at the synaptic site. J Neurosci 8:176184.

Steward O, Davis L, Dotti C, Phillips LL, Rao A, Banker G (1988) Protein synthesis and processing in cytoplasmic microdomains beneath postsynaptic sites on CNS neurons: a mechanism for establishing and maintaining a mosaic postsynaptic receptive surface. Mol Neurobiol 2:227-261.

Steward O, Torre ER, Phillips LL, Trimmer PA (1990) The process of reinnervation in the dentate gyrus of adult rats: time course of increases in mRNA for glial fibrillary acidic protein. J Neurosci 10: $2373-2384$
Strong MJ, Svedmyr A, Gajdusek DC, Garruto RM (1990) The temporal expression of amyloid precursor protein mRNA in vitro in dissociated hippocampal neuron cultures. Exp Neurol 109:171-179.

Sundell CL, Singer RH (1990) Actin mRNA localizes in the absence of protein synthesis. J Cell Biol 111:2397-2403.

Sundell CL, Singer RH (1991) Requirement of microfilaments in sorting of actin messenger RNA. Science 253:1275-1277.

Terrian DM, Johnston D, Claiborne BJ, Ansah-Yiadom R, Strittmatter WJ, Rea MA (1988) Glutamate and dynorphin release from a subcellular fraction enriched in hippocampal mossy fiber synaptosomes. Brain Res Bull 21:343-351.

Terrian DM, Damron DS, Dorman RV, Gannon RL (1989a) Effects of calcium antagonists on the evoked release of dynorphin $A(1-8)$ and availability of intraterminal calcium in rat hippocampal mossy fiber synaptosomes. Neurosci Lett 106:322-327.

Terrian DM, Hernandez PG, Rea MA, Peters RI (1989b) ATP release, adenosine formation, and modulation of dynorphin and glutamic acid release by adenosine analogues in rat hippocampal mossy fiber synaptosomes. I Neurochem 53:1390-1399.

Terrian DM, Gannon RL, Rea MA (1990) Glutamate is the endogenous amino acid selectively released by rat hippocampal mossy fiber synaptosomes concomitantly with prodynorphin-derived peptides. Neurochem Res 15:1-5.

Tiedge H, Fremeau RT, Weinstock PH, Arancio O, Brosius J (1991) Dendritic location of neural BC1 RNA. Proc Natl Acad Sci USA 88: 2093-2097.

Torre ER, Steward O (1992) Demonstration of local protein synthesis within dendrites using a new culture system that permits the isolation of living axons and dendrites from their cell bodies. J Neurosci 12 ; $762-772$.

Trapp BD, Moench T, Pulley M, Barbosa E, Tennekoon G, Griffin J (1987) Spatial segregation of mRNA encoding myelin-specific proteins. Proc Natl Acad Sci USA 84:7773-7777.

Trimmer PA, Phillips LL, Steward O (1991) Combination of in situ hybridization and immunocytochemistry to detect messenger RNAs in identified CNS neurons and glia in tissue culture. J Histochem Cytochem 39:891-898.

Tucker RP, Garner CC, Matus A (1989) In situ localization of microtubule-associated protein mRNA in the developing and adult rat brain. Neuron 2:1245-1256.

Vance JE, Pan D, Vance DE, Campenot RB (1991) Biosynthesis of membrane lipids in rat axons. J Cell Biol 1 15:1061-1068.

Watson JB, Battenberg EF, Wong KK, Bloom FE, Sutcliffe JG (1990) Subtractive cDNA cloning of RC3, a rodent cortex-enriched mRNA encoding a novel 78 residue protein. J Neurosci Res 26:397-408.

Watson JB, Sutcliffe JG, Fisher RS (1992) Localization of the protein kinase C phosphorylation/calmodulin-hinding substrate RC.3 in dendritic spines of neostriatal neurons. Proc Natl Acad Sci USA 89:85818585.

Webster H deF, Lamperth L, Favilla JT, Lemke G, Tesin D, Manuelidis L (1987) Use of a biotinylated probe and in situ hybridization for light and electron microscopic localization of $P_{0}$ mRNA in myelinforming Schwann cells. Histochemistry 86:441-444.

Weiler IJ, Greenough WT (1991) Potassium ion stimulation triggers protein translation in synaptoneurosomal polyribosomes. Mol Cell Neurosci 2:305-314.

Wenzel J, Lammert G, Meyer U, Krug M (1991) The influence of long-term potentiation on the spatial relationship between astrocyte processes and potentiated synapses in the dentate gyrus neuropil of rat brain. Brain Res 560:122-131.

Wilson CJ (1984) Passive cable properties of dendritic spines and spiny neurons. J Neurosci 4:281-297.

Wu K, Huang Y, Adler J, Black IB (1992) On the identity of the major postsynaptic density protein. Proc Natl Acad Sci USA 89:301 5-3019.

Yaffe D, Nudel U, Mayer Y, Neuman S (1985) Highly conserved sequences in the $3^{\prime}$ untranslated region of mRNAs coding for homologous proteins in distantly related species. Nucleic Acids Res 13: 3723-3737.

Yisraeli JK, Sokol S, Melton DA (1990) A two-step model for the localization of maternal mRNA in Xenopus oocytes: involvement of microtubules and microfilaments in the translocation and anchoring of $\mathrm{Vgl} \mathrm{mRNA}$. Development 108:289-298. 